Printed

May 27, 1988

\title{
CALCULATION OF OXYGEN DIFFUSION IN PLUTONIUM OXIDE FILMS DURING THE HIGH-TEMPERATURE OXIDATION OF PLUTONIUM-1 WEIGHT PERCENT GALLIUM IN 500 TORR OF AIR
}

Jerry L. Stakebake

R. L. Thomas, Editor

I. C. Delaney, Compositor

SUBJECT DESCRIPTORS

Plutonium Oxidation

Plu tonium Oxide

Diffusion

Oxygen Diffusion

Metal Oxidation

ROCKWELL INTERNATIONAL

AEROSPACE OPERATIONS

ROCKY FLATS PLANT

P. O. BOX 464

GOLDEN, COLORADO 80402-0464

Prepared under Contract DE-AC04-76DPO3533

for the

Albuquerque Operations Office

U.S. Department of Energy 


\section{DISCLAIMER}

This report was prepared as an account of work sponsored by an agency of the United States Government. Neither the United States Government nor any agency Thereof, nor any of their employees, makes any warranty, express or implied, or assumes any legal liability or responsibility for the accuracy, completeness, or usefulness of any information, apparatus, product, or process disclosed, or represents that its use would not infringe privately owned rights. Reference herein to any specific commercial product, process, or service by trade name, trademark, manufacturer, or otherwise does not necessarily constitute or imply its endorsement, recommendation, or favoring by the United States Government or any agency thereof. The views and opinions of authors expressed herein do not necessarily state or reflect those of the United States Government or any agency thereof. 


\section{DISCLAIMER}

Portions of this document may be illegible in electronic image products. Images are produced from the best available original document. 
RFP-3790

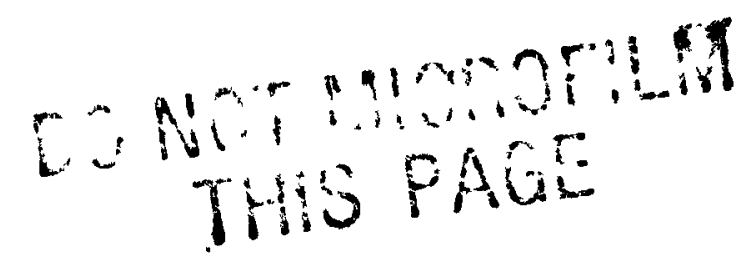

ii 


\section{CONTENT S}

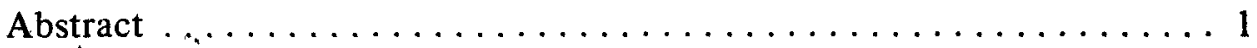

Introduction $\ldots \ldots \ldots \ldots \ldots \ldots \ldots \ldots \ldots \ldots \ldots \ldots \ldots \ldots \ldots \ldots \ldots$

Experimental. . . .

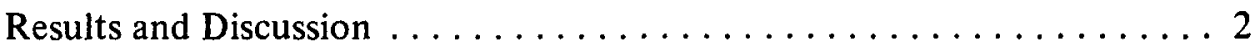

Evaluation of Oxide Formation. . . . . . . . . . . . . . 2

Oxidation Kinetics $\ldots \ldots \ldots \ldots \ldots \ldots \ldots \ldots \ldots \ldots \ldots \ldots \ldots \ldots$

Oxygen Diffusion in Plutonium Dioxide $\ldots \ldots \ldots \ldots \ldots \ldots$

Pressure Dependence of Oxygen Diffusion $\ldots \ldots \ldots \ldots \ldots$

Effect of Oxide Structure on Oxygen Diffusion ........... 5

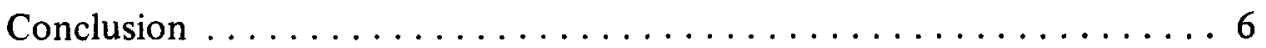

References......................... 
RFP-3790

\section{A CKNOW LEDGM EN T}

The author is indebted to Dr. John Haschke for discussions regarding this manuscript. 


\title{
CALCULATION OF OXYGEN DIFFUSION IN PLUTONIUM OXIDE FILMS DURING THE HIGH-TEMPERATURE OXIDATION OF PLUTONIUM-1 WEIGHT PERCENT GALLIUM IN 500 TORR OF AIR
}

\author{
Jerry L. Stakebake
}

\begin{abstract}
Oxygen self-diffusion in $\mathrm{PuO}_{1.995}$ was calculated from rate constants obtained for the parabolic oxidation of the Pu-1 wt\% Ga alloy in 500-torr dry air between 250 and $480{ }^{\circ} \mathrm{C}$. Diffusion is described by the equation

$$
\mathrm{D}=1.2 \times 10^{-6} \exp (-22,600 / \mathrm{RT}) \mathrm{m}^{2} / \mathrm{sec}
$$

The activation energy for oxygen vacancy diffusion in the n-type $\mathrm{PuO}_{2-\mathrm{x}}$ is $22.6 \mathrm{kcal} / \mathrm{mole}$. Results from this investigation are compared with other reported results, and a possible explanation for the difference in results is discussed.
\end{abstract}

\section{INTRODUCTION}

Plutonium is a very reactive metal that oxidizes readily when exposed to air, oxygen, or water vapor. In earlier work, ${ }^{1}$ the high-temperature oxidation of plutonium in dry air was described by a three-stage process. Stage I involves the growth of an oxide film with a diffusion controlled parabolic rate. Stage II consists of a region of linear kinetics where the rate controlling process is thought to be the diffusion of oxygen through a dense plutonium dioxide film that has essentially reached a constant thickness. Stage III is a second linear process produced by the cracking and spalling of the oxide film.

The exact nature of the oxide film involved in Stages I and II is still uncertain. Phase diagrams for the plutonium oxygen system indicate a mixed phase of cubic $\mathrm{PuO}_{2-\mathrm{x}}$ and cubic $\mathrm{PuO}_{1.52}$ $\left(\alpha-\mathrm{Pu}_{2} \mathrm{O}_{3}\right)$ at temperatures below $300{ }^{\circ} \mathrm{C}$ and $\mathrm{PuO}_{2-\mathrm{x}}$ plus $\mathrm{PuO}_{1.61}$ above $300^{\circ} \mathrm{C} .^{2,3} \mathrm{X}$-ray studies $^{4}$ of the oxidation of plutonium show that $\mathrm{PuO}_{1.52}$ is produced in low oxygen pressures at $305^{\circ} \mathrm{C}$. When the temperature was increased to $420^{\circ} \mathrm{C}$, the primary oxide formed was referred to as PuO. Larson and Haschke ${ }^{5}$ subsequently showed that the PuO phase is actually the oxide carbide $\mathrm{PuO}_{\mathrm{x}} \mathrm{C}_{\mathrm{y}}$. In any case, this phase appears to exist only as a thin film and is readily oxidized to $\mathrm{PuO}_{1.52}$ and $\mathrm{PuO}_{2}$.

The focus of this work was the Stage I oxidation process that forms a dense plutonium dioxide film and results in the diffusion controlled kinetics. Oxidation kinetics of Pu-1 wt\% Ga were evaluated using the parabolic rate law. Oxygen self-diffusion coefficients were then calculated from the parabolic rate constants and compared to the results obtained using other methods. ${ }^{6-9}$ Activation energies for diffusion and parabolic oxidation were also calculated.

\section{EXPERIMENTAL}

The $\mathrm{Pu}-1$ wt $\%$ Ga alloy used in this investigation and the experimental procedures for measuring the oxidation kinetics have been described elsewhere. ${ }^{1}$ This alloy contained $502 \mathrm{ppm}$ of impurities in addition to the gallium. Oxidation kinetics were determined using a Cahn vacuum microbalance. Measurements were carried out in 500-torr dry air (105-torr $\mathrm{O}_{2}$ ) over the temperature range 250$500{ }^{\circ} \mathrm{C}$. A data acquisition system was used to continuously collect data throughout the three-stage oxidation process. Data relating to the parabolic Stage I process were separated and analyzed by computer. Samples from coupons oxidized through the Stage I process were analyzed by metallography and $x$-ray diffraction to determine if more than one type of oxide was present. 


\section{RESULTS AND DISCUSSION}

\section{Evaluation of Oxide Formation}

The exact composition of the oxide film formed during the parabolic oxidation of plutonium is unknown. The oxide product formed was analyzed by $\mathrm{x}$-ray diffraction and the results showed only a single fcc $\mathrm{PuO}_{2}$ phase with a lattice parameter of $5.398 \pm 0.002 \AA$. The slightly expanded lattice $(5.398 \AA$ compared to $5.396 \pm$ $0.0003 \AA$ for stoichiometric $\mathrm{PuO}_{2.00}$ ) indicates a composition of $\mathrm{PuO}_{2-\mathrm{x}}$. Gardner et al. ${ }^{2}$ reported the lattice parameter for $\mathrm{PuO}_{1.98}$ to be $5.405 \pm$ $0.002 \AA$. The $\mathrm{PuO}_{2-\mathrm{x}}$ film observed in this study would then have a composition between $\mathrm{PuO}_{1.98}$ and $\mathrm{PuO}_{2.00}$. Assuming Vegard's law, the composition would be $\mathrm{PuO}_{1.995}$. No x-ray evidence was found for the formation of the bcc $\mathrm{PuO}_{1.52}$ $\left(\alpha-\mathrm{Pu}_{2} \mathrm{O}_{3}\right)$ phase. A cross section through the oxidized metal sample was examined by metallography and also showed no visible evidence of multiple oxide film formation. However, in this nonequilibrium system, it is still probable that a reduced oxide film near $\mathrm{PuO}_{1.52}$ is present at the metal interface.

\section{Oxidation Kinetics}

The mechanism for plutonium oxidation depends upon the nature of the oxide film being formed. The primary factor to be considered is whether the oxide is compact or porous. A compact oxide acts as a barrier separating the metal from oxygen. Oxidation rates then depend on the solid-state diffusion of oxygen through the oxide. As the oxide grows, the diffusion distance increases and the reaction rate decreases with time. This process has been observed in the initial oxidation of plutonium and explained by the parabolic rate model.

Oxidation of $\mathrm{Pu}-1 \mathrm{wt} \% \mathrm{Ga}$ in 500 torr of air is illustrated in Figure 1. This run was made at $405{ }^{\circ} \mathrm{C}$ and is typical of all the oxidation runs made below about $480{ }^{\circ} \mathrm{C} .^{1}$ A parabolic growth of the oxide film began at time zero and eventually transformed into a linear rate of oxidation. At temperatures above about $480^{\circ} \mathrm{C}$, the oxidation process was linear throughout the run.

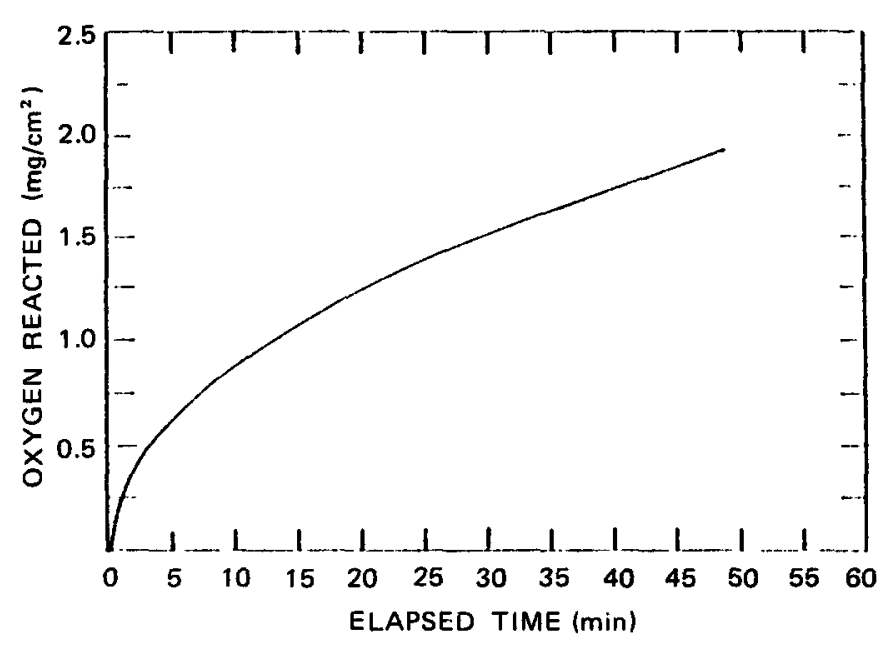

FIGURE 1. Parabolic oxidation of Pu-1 wt $\% \mathrm{Ga}$ at $405{ }^{\circ} \mathrm{C}$ in 500 Torr of Air

Parabolic oxidation kinetics were evaluated using the equation

$$
\mathrm{x}^{2}=\mathrm{k}_{\mathrm{p}} \mathrm{t}+\mathrm{C}
$$

where $x$ is the ainount of oxygen reacted $\left(\mathrm{mg} / \mathrm{cm}^{2}\right)$, $\mathrm{k}_{\mathrm{p}}$ is the parabolic rate constant, and $\mathrm{C}$ is the integration constant. The activation energy for this process was determined from the temperature dependence of $k_{p}$ by using the Arrhenius equation

$$
k_{p}=A \exp \left(-E_{a} / R T\right)
$$

A plot of this equation is shown in Figure 2. The activation energy for the parabolic oxidation process was calculated to be $23.4 \mathrm{kcal} / \mathrm{mole}$. Since parabolic kinetic behavior is typically caused by the formation of a dense product layer, the rate limiting step is the diffusion of oxygen through this oxide. In this situation, the activation energy for parabolic oxidation is also the activation energy for oxygen diffusion.

\section{Oxygen Diffusion in Plutonium Dioxide}

The theory of parabolic oxidation has been described by Wagner. ${ }^{10}$ This theory assumes that the volume diffusion of reacting ions (corresponding point defects) or the transport of electrons across 
RFP-3790

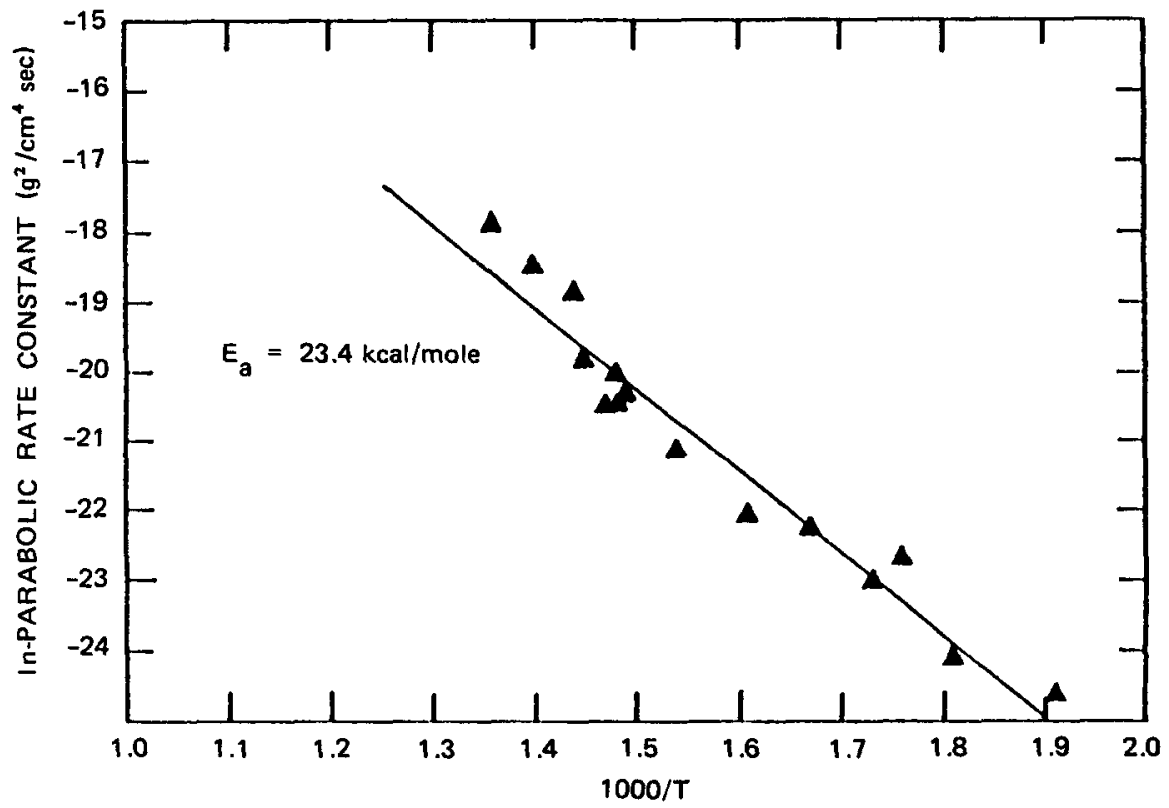

FIGURE 2. Temperature Dependence of the Parabolic Oxidation Rate Constants for Pu-1 wt \% Ga Oxidation in 500-Torr Air

the oxide layer is the rate-determining process. Reaction at the metal-oxide interface is then very rapid. Rate controlling lattice diffusion occurs by the formation of point defects with different types of defects resulting in different diffusion mechanisms.

Wagner ${ }^{11,12}$ derived an expression for relating parabolic rate constants and diffusion coefficients. Wach ${ }^{13,14}$ further related the rational rate coefficient used by Wagner to the parabolic rate coefficient, $k_{p}$, and the diffusion coefficient, $D$, for oxygen diffusion in $\mathrm{V}_{2} \mathrm{O}_{5}$. This method has now been applied to the oxygen/plutonium dioxide system. The diffusion coefficient for oxygen diffusion in $\mathrm{PuO}_{1.995}$ was determined from the experimentally determined parabolic rate constant, $\mathrm{k}_{\mathrm{p}}$, by the equation

$$
\mathrm{k}_{\mathrm{p}}=2 \mathrm{DW} \mathrm{W}^{2} \rho^{2}
$$

where $\mathrm{W}$ is the mass fraction of oxygen in $\mathrm{PuO}_{2}$ and $\rho$ is the density of $\mathrm{PuO}_{2}$.

Following the calculation of the diffusion coefficients as a function of temperature, the activation energy for diffusion may be determined from the Arrhenius relationship

$$
\mathrm{D}=\mathrm{D}_{0} \exp \left(-\mathrm{Q}_{\mathrm{D}} / \mathrm{RT}\right)
$$

Evaluation of numerous data on the diffusion of hydrogen in metals and non-metals revealed a linear dependence between the logarithm of $D$ or $D_{0}$ and the activation energy $Q_{D} \cdot{ }^{15}$ This relationship can be described by the equation

$$
D_{0}=D_{\theta} \exp \left(Q_{D} / R \theta\right)
$$

where $D_{\theta}$ is the intercept at $Q_{D}=0$ and $\theta$ has units of temperature. At any temperature, $T$, the diffusion coefficient is given by

or

$$
\mathrm{D}=\mathrm{D}_{\theta} \exp \left(\mathrm{Q}_{\mathrm{D}} / \mathrm{R} \theta\right) \exp \left(-\mathrm{Q}_{\mathrm{D}} / \mathrm{RT}\right)
$$

$$
D=D_{\theta} \exp \left(Q_{D} / R \theta-Q_{D} / R T\right)
$$

This relationship is significant in that it permits the determination of the activation energy for a diffusion process from a single value of the diffusion coefficient. Numerical values for $D_{\theta}$ and $\theta$ have been determined directly from $\log D_{0}$ versus 
$\mathrm{Q}_{\mathrm{D}}$ plots. ${ }^{15}$ Since $\mathrm{D}_{\theta}$ and $\theta$ are characteristics of the diffusant, they also may be determined independently. The constant $\mathrm{D}_{\theta}$ was derived from Heisenberg's uncertainty principle and is given by

$$
\mathrm{D}_{\theta}=\mathrm{h} / 4 \pi \mathrm{m}
$$

For oxygen, $D_{\theta}$ is equal to $1.99 \times 10^{-9} \mathrm{~m}^{2} / \mathrm{sec}$. The constant $\theta$ is the vibrational characteristic temperature and is determined by

$$
\theta=\mathrm{h} v / \mathrm{k}
$$

Oxygen has a calculated value for $\theta$ of $22.30 \mathrm{~K}^{16}$ while the value determined experimentally was $2010 \mathrm{~K}^{15}$

Diffusion coefficients for oxygen diffusion in $\mathrm{PuO}_{1.995}$ were calculated from the parabolic rate constants obtained for the oxidation of the Pu-1 wt $\%$ Ga alloy in 500 torr of dry air. These results are summarized in Table 1. Data were obtained over the temperature range 250 to $465{ }^{\circ} \mathrm{C}$. The $Q_{D}$ values included in this table were obtained using the single point method of Equation 7. The average value for all runs was $20.3 \mathrm{kcal} / \mathrm{mole}$, which compares favorably with the value of 22.6 $\mathrm{kcal} / \mathrm{mole}$ obtained from the Arrhenius plot of Figure 3. This value is essentially identical with the $22 \mathrm{kcal} / \mathrm{mole}$ calculated from Figure 2 for the activation energy of parabolic oxidation. Diffusion of oxygen in $\mathrm{PuO}_{1.995}$, at a single oxygen partial pressure of 105 torr, can be described by the equation

$$
\mathrm{D}=1.2 \times 10^{-6} \mathrm{exp}(-22,600 / \mathrm{RT})
$$

Results from this investigation compare favorably with the limited number of results available from earlier studies. ${ }^{6-9}$ Curves $A^{6}$ and $B^{7}$ in Figure 3 were obtained by an isotope exchange method using stoichiometric $\mathrm{PuO}_{2.00}$. The activation energy for oxygen diffusion in these materials was 45 and $42 \mathrm{kcal} /$ mole respectively. Diffusion coefficients in Curve $\mathrm{C}^{8}$ were determined by the gravimetric oxidation of $\mathrm{PuO}_{2-\mathrm{x}}$. The activation energy for oxygen vacancy diffusion was $11 \mathrm{kcal} /$ mole. The single value at point $D^{9}$ was obtained from electrical resistivity measurements of $\mathrm{PuO}_{1.98}$. Activation energies for self-diffusion were calculated
TABLE 1. Self-Diffusion of Oxygen in $\mathrm{PuO}_{1.995}$

\begin{tabular}{|c|c|c|c|}
\hline $\begin{array}{c}\text { Temperature } \\
\left({ }^{\circ} \mathrm{C}\right) \\
\end{array}$ & $\begin{array}{c}k_{\mathrm{p}} \\
\left(\mathrm{g}^{2} / \mathrm{cm}^{4} \sec \times 10^{11}\right) \\
\end{array}$ & $\begin{array}{c}\text { D } \\
\left(\mathrm{m}^{2} / \mathrm{sec} \times 10^{16}\right) \\
\end{array}$ & $\begin{array}{c}\mathrm{Q}_{\mathrm{D}}{ }^{*} \\
\text { (kcal/mole) }\end{array}$ \\
\hline 251 & 2.00 & 5.46 & 20.5 \\
\hline 279 & 3.40 & 9.28 & 21.2 \\
\hline 296 & 14.20 & 38.8 & 19.9 \\
\hline 304 & 9.89 & 27.0 & 20.9 \\
\hline 326 & 21.60 & 59.0 & 20.7 \\
\hline 350 & 26.10 & 71.1 & 21.5 \\
\hline 377 & 64.60 & 176 & 21.2 \\
\hline 400 & 147 & 401 & 20.6 \\
\hline 401 & 196 & 536 & 20.2 \\
\hline 402 & 130 & 354 & 21.1 \\
\hline 405 & 127 & 346 & 21.3 \\
\hline 417 & 244 & 666 & 20.4 \\
\hline 422 & 642 & 1750 & 18.7 \\
\hline 442 & 948 & 2590 & 18.7 \\
\hline \multirow[t]{2}{*}{464} & 1680 & 4570 & 18.3 \\
\hline & & Average & 20.3 \\
\hline
\end{tabular}
During the Parabolic Oxidation of Plutonium-1 Weight Percent Gallium in 500 Torr of Air

*Determined by Equation 7.

FIGURE 3. Temperature Dependence for Oxygen Self-Diffusion Coefficients in Plutonium Dioxide

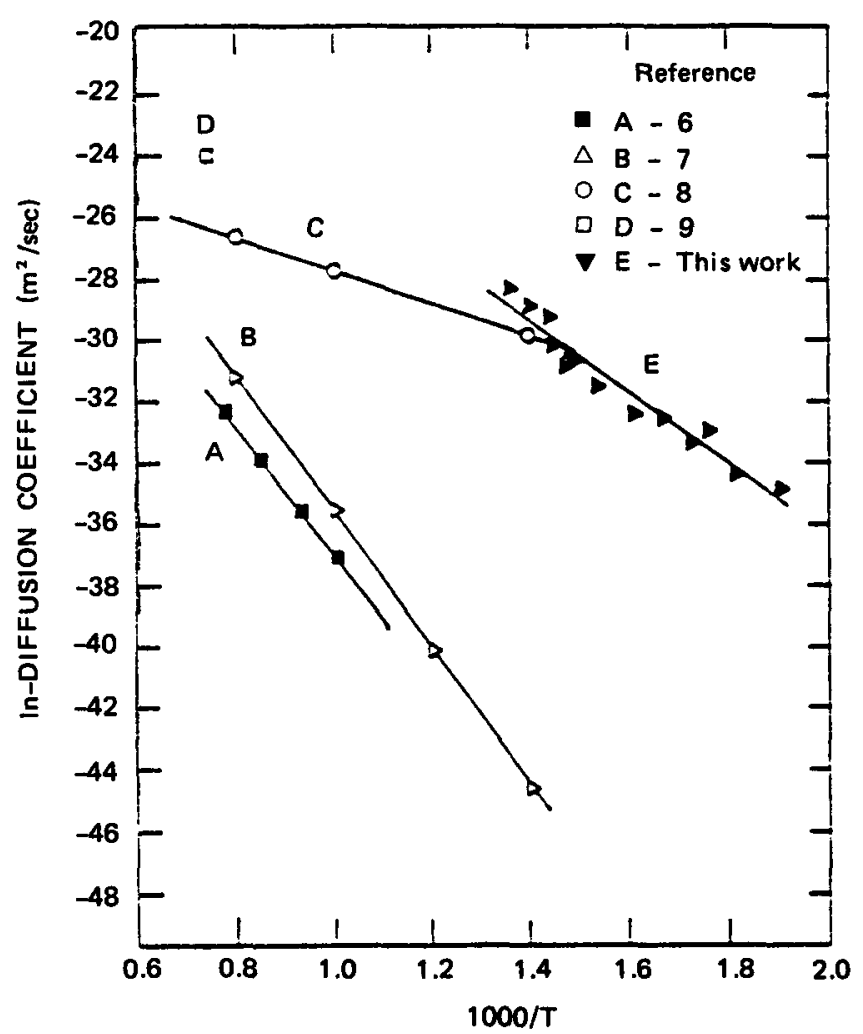




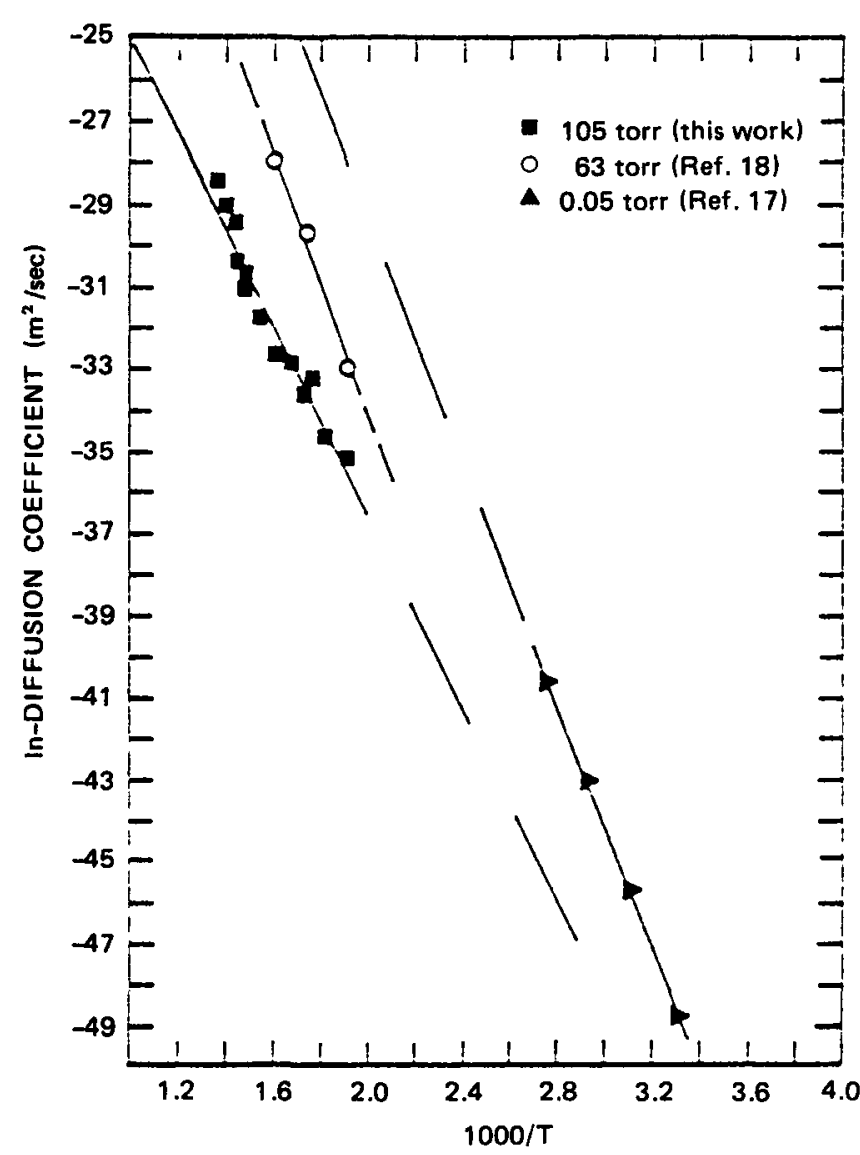

FIGURE 4. Effect of Oxygen Partial Pressure on the Oxygen Diffusion Coefficients

using Equation 7 described above. For $\mathrm{PuO}_{1.98}$ the value was $26 \mathrm{kcal} / \mathrm{mole}$.

\section{Pressure Dependence of Oxygen Diffusion}

The pressure dependence of the oxygen diffusion coefficient is influenced by the mechanism for oxygen transfer through the oxide film. In general, if the diffusion coefficient is directly proportional to pressure, oxygen diffuses by an interstitial mechanism. If the dependence is inversely proportional to pressure, diffusion is controlled by an oxygen vacancy mechanism.

Larson and $\mathrm{Cash}^{17}$ measured the parabolic oxidation of $\mathrm{Pu}-1 \mathrm{wt} \% \mathrm{Ga}$ in 0.05 -torr oxygen in the temperature range $30-90{ }^{\circ} \mathrm{C}$. Oxygen diffusion coefficients were calculated from these data using Equation 3. Figure 4 compares these results with those calculated from the current high-temperature study. Activation energies for diffusion were in reasonable agreement for the two studies, $30 \mathrm{kcal} / \mathrm{mole}$ at low temperature and pressure compared to $22.6 \mathrm{kcal} /$ mole at high temperature and pressure. Earlier data obtained by Stakebake ${ }^{18}$ for $\mathrm{Pu}-1$ wt\% Ga oxidation in 300 torr of air ( 63 torr of $\mathrm{O}_{2}$ ) also were used to evaluate the pressure effects on diffusion coefficients. Data obtained between 250 and $350^{\circ} \mathrm{C}$ are included in Figure 4 . The activation energy for diffusion under these conditions was 33 $\mathrm{kcal} / \mathrm{mole}$. The agreement between activation energies is indicative of similar diffusion processes. These data show an inverse pressure dependence for diffusion, which supports an oxygen vacancy diffusion mechanism.

\section{Effect of Oxide Structure on Oxygen Diffusion}

The complete phase diagram for the plutonium/ oxygen system has not been firmly established and may be more complex than currently recognized. ${ }^{19}$ In the nonstoichiometric region below $300^{\circ} \mathrm{C}$, the phase diagram for the plutonium/oxygen system shows the existence of two oxide phases for oxygen/plutonium ratios between 1.5 and $2.0 .^{2}$ (See Figure 5.) One is an fcc $\mathrm{PuO}_{2-\mathrm{x}}$ and the other a bcc $\mathrm{PuO}_{1.52}$. The bcc phase converts to $\mathrm{PuO}_{1.61}$ during oxidation at temperatures above $300^{\circ} \mathrm{C}$. $\mathrm{McNeilly}{ }^{20}$ measured the resistivity and thermoelectric properties of plutonium oxides and found them to exhibit typical oxide semiconductor properties. Oxides with compositions between 1.72 and 1.92 are p-type semiconductors at temperatures up to $300{ }^{\circ} \mathrm{C}$ due to the presence of $\mathrm{PuO}_{1.52}$ with its large number of vacant sites. On oxidation above $300{ }^{\circ} \mathrm{C}$, this oxide converts to an oxygen deficient $\mathrm{PuO}_{2-\mathrm{x}}$, which is an n-type semiconductor. The temperature for oxide transformation from $\mathrm{PuO}_{1.52}$ (p-type) to $\mathrm{PuO}_{2-\mathrm{x}}$ (n-type) increases with decreasing oxygen/plutonium composition. The cubic oxide $\mathrm{PuO}_{1.985}$ remains n-type down to room temperature. Therefore, depending upon the oxidation temperature and oxide composition, the oxide may exhibit p- or $n$-type properties and contiguous layers may have a p-n junction, which can affect the diffusion process. 


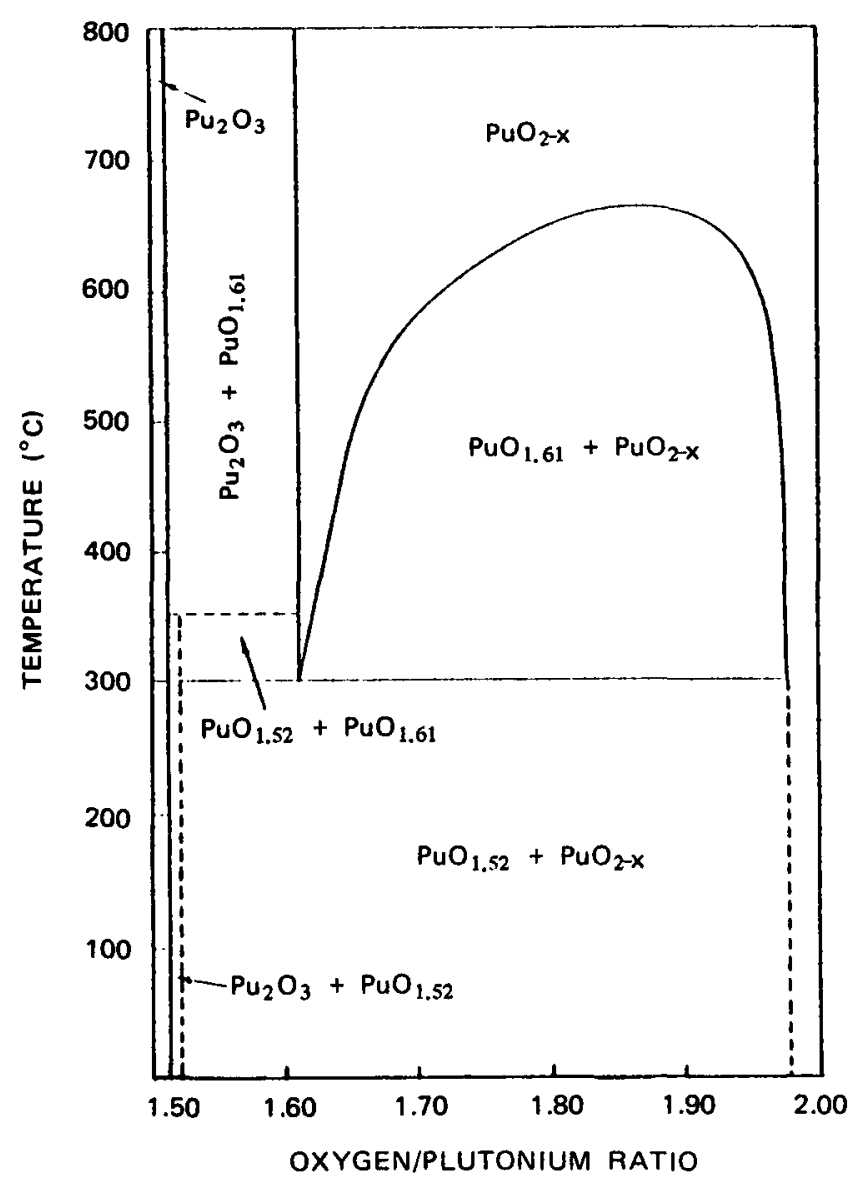

FIGURE 5. Plutonium/Oxygen Phase Diagram (Reference 2)

The defect structure in the plutonium oxide system is an anion type. Stoichiometric $\mathrm{PuO}_{2.00}$ is assumed to have Frenkel-type defects. ${ }^{21}$ In this case, the defect pair consists of both oxygen vacancies and interstitials $\left(\mathrm{V}_{0}, \mathrm{O}_{\mathrm{i}}\right)$. Substoichiometric n-type $\mathrm{PuO}_{2-\mathrm{x}}$ is oxygen deficient and the point defects are oxygen vacancies. The p-type oxide has an excess of oxygen with respect to the $\mathrm{PuO}_{1.52}$ stoichiometry, e.g., $\mathrm{PuO}_{1.52+y}$ with the oxygen being located in interstitial positions. Oxygen diffusion in the plutonium oxides described occurs by the migration of either oxygen vacancies or interstitials. The driving force for oxygen diffusion during oxidation is the free energy change associated with the formation of oxide from plutonium metal and oxygen gas. This potential difference is seen in the concentration gradient across the oxide film and drives oxygen diffusion. The rate of oxide growth is determined by the gradient and is proportional to the rate of diffusion of oxygen. This mechanism leads to the parabolic rate of oxidation and provides the basis for measuring the diffusion coefficient.

Activation energies for diffusion may be grouped into two categories based on the properties of the oxide. Data for stoichiometric $\mathrm{PuO}_{2.00}$ are in good agreement with an average activation energy of $43.5 \mathrm{kcal} / \mathrm{mole}$. This material has a Frenkel $\left(\mathrm{V}_{0}, \mathrm{O}_{\mathrm{j}}\right)$ defect structure, which has an energy of formation of about $70 \mathrm{kcal} / \mathrm{mole}^{9}$ At the oxidation temperatures of this investigation, it behaves like a p-type semiconductor with oxygen interstitials. The lower diffusion coefficient, higher activation energy, may well be caused by the restriction for interstitial ions in this stoichiometric fluorite phase. The average activation energy for five (Figures 3 and 4) substoichiometric $\mathrm{PuO}_{2-\mathrm{x}}$ samples was $24.5 \mathrm{kcal} / \mathrm{mole}$. This material is n-type with inherent oxygen vacancies providing the vehicle for oxygen diffusion. Dependence of oxygen diffusion on the oxygen/plutonium ratio may account for the variation in diffusion coefficients and activation energies being reported.

\section{CONCLUSION}

Oxygen diffusion through the plutonium oxide film formed during the oxidation of plutonium was evaluated. The only oxide detected was identified by $\mathrm{x}$-ray diffraction as an fcc $\mathrm{PuO}_{1.995}$. However, because of the nonequilibrium system, the presence of a bcc $\mathrm{PuO}_{1.52}$ film at the oxide/metal interface is suspected. The thickness calculated for the rate controlling dense oxide layer was on the order of 15 to $25 \mu \mathrm{m}$. If this film were $\mathrm{PuO}_{1.52}$, it easily would have been identified by $\mathrm{x}$-ray diffraction and metallography. Therefore, the rate controlling oxide is assumed to be $\mathrm{PuO}_{2-\mathrm{x}}$ and any $\mathrm{PuO}_{1.52}$ present would exist as a very thin film. Oxygen diffusion coefficients were calculated from the parabolic rate constants for the air oxidation of $\mathrm{Pu}-1$ wt\% Ga. These coefficients compared well with those previously reported for oxygen diffusion in $\mathrm{PuO}_{2-\mathrm{x}}$. Any differences may be the result of differences in oxide composition or oxygen partial pressure. The difference between the results obtained for $\mathrm{PuO}_{1.995}$ and those reported for stoichiometric $\mathrm{PuO}_{2.00}$ may well be due to two 
different diffusion mechanisms. The $\mathrm{PuO}_{1.995}$ was an n-type semiconductor with oxygen vacancies providing the vehicle for oxygen diffusion. The activation energy for diffusion in $\mathrm{PuO}_{1.995}$ was $22.6 \mathrm{kcal} / \mathrm{mole}$, which was nearly identical with the activation energy of $23.4 \mathrm{kcal} / \mathrm{mole}$ obtained for the parabolic oxidation of plutonium. Evidence indicates that the diffusion coefficient increases and the activation energy for diffusion decreases as the oxygen/plutonium composition decreases for fcc $\mathrm{PuO}_{2-\mathrm{x}}$. Higher diffusion coefficients and lower activation energies are expected for bcc $\mathrm{PuO}_{1.52}$. A technique for calculating activation energies from single values of the diffusion coefficient was evaluated. This activation energy was in agreement with the value calculated from the Arrhenius equation.

\section{REFERENCES}

1. J. L. Stakebake, J. Less-Common Met., 123, p 185, 1987.

2. E. R. Gardner, T. L. Marken, and R. S. Street, J. Inorg. Nucl. Chem., 27, p 541, 1965.

3. T. D. Chikalla, C. E. McNeilly, and R. E. Skavdahl, J. Nucl. Mater., 12, p 131, 1964.

4. K. Terada, R. L. Meisel, and M. R. Dringman, J. Nucl. Mater., 30, p 340, 1969.

5. D. T. Larson and J. M. Haschke, Inorg. Chem., 20, p 1945, 1981.

6. R. L. Deaton and C. J. Wiedenheft, J. Inorg. Nucl. Chem., 35, p 649, 1973.

7. A. S. Bayoglu, A. Giordano, and R. Lorenzelli, J. Nucl. Mater., 113, p 71, 1983.

8. A. S. Bayoglu and R. Lorenzelli, J. Nucl. Mater., 82, p 4031979.
9. P. Chereau and J. F. Wadier, J. Nucl. Mater., 46, p 1, 1973.

10. C. Wagner, Z. Physik. Chem., B21, p 25, 1933.

11. C. Wagner, "Atom Movements," p 153, Amer. Soc. Metals, Cleveland, $\mathrm{OH}, 1951$.

12. P. Kofstad, "High-Temperature Oxidation of Metals," p 119, John Wiley \& Sons, New York, NY, 1966.

13. S. P. Wach, Proceedings Spring Residential Conf. on Environmental Degradation of High Temperature Materials, March 1980 , Ser. 3, No. 13, Vol. 2, p i/1, Institution of Metallurgists, London, 1980.

14. A. Mukherjee and S. P. Wach, J. Less-Common Met., 92, p 289, 1983.

15. S. P. Wach, Proc. 2nd Int. Conf. on Hydrogen in Metals, Paris, June 1977, Pergamon, Oxford, 1978.

16. T. Hill, Statistical Thermodynamics, AddisonWesley, Reading, MA, 1960.

17. D. T. Larson and D. L. Cash, J. Phys. Chem., 73, p 2814, 1969.

18. J. L. Stakebake, J. Electrochem. Soc., 124, p 460, 1977.

19. J. M. Haschke et al., The Reaction of Plutonium With Water. Kinetic and Equilibrium Behavior of Binary and Ternary Phases in the Pu+O-OH System, RFP-3416, Rockwell International, Rocky Flats Plant, Golden, CO, 1983.

20. C. E. McNeilly, J. Nucl. Mater., 11, p 53, 1964.

21. C. A. Colmenares, Progress in Solid State Chemistry, 9, p 139, J. McCaldin and G. Somorjai, Eds., Pergamon Press, New York, NY, 1974. 
RFP-3790 